conditions : (1) when the hæo morrhage has not been excessive and the maternal pulse is full and its rate not above 100 per minute; (2) when the cervix is undilated and appears to be unduly rigid, indicating that dilatation is likely to be slow and difficult, as is often the case in elderly primiparz; (3) when the surgeon can be confident that there is no risk of sepsis from previous frequent vaginal examinations, \&c. ; (4) the pregnancy should have reached full term or very nearly so, and the foetal heart sounds must be good; (5) another factor which should influence the surgeon in deciding in favour of Cæsarean section is the co-existence of some disproportion between the size of the foetal head and the maternal pelvis ; and (6), as in the case here described, when the parents are especially desirous of a live child. The following case will serve to illustrate these points :-

The patient, a Eurasian aged 32, was admitted under my care to the maternity department of the Sassoon Hospital, Poona, on Oct. 19th, 1915. She had been married 12 years, and the present was her first pregnancy. The last period ended on Jan. 11th, 1915; the probable date of confinement would be about Oct. 16th, 1915. The patient stated that she had had slight pains for about 36 hours; bleeding began a few hours before she came to hospital. No vaginal examination had been made previous to her admission to hospital. When I saw her she was having feeble pains at about half-hourly intervals. Her general condition was excellent, the pulse being full and its rate 80 per minute the face was placid and the tongue clean and moist. On abdominal examination the child was found to be in the first vertex position and the fotal heart sounds were good. The pelvic measurements were normal. On vaginal examination there was still a definite and fairly firm cervix, which admitted one finger only; at the internal os only placental tissue could be reached.

Both the patient and her husband were very desirous of having a live child, and considering all the points of her case, I felt justified in advising abdominal section. Cæasarean section was therefore performed and a full-time live child was delivered. The bleeding from the placental site was somewhat excessive and for a moment rather disconcerting; it was certainly more than I had noted in cases of Cæsarean section in which the placenta was normally implanted. During the first few days after the operation there was a good deal of trouble from after-pains; otherwise the patient made an uneventful recovery, and both mother and child were discharged quite well on Nov. 27 th.

My thanks are due to Lieutenant-Oolonel A. Hooton, I.M.S., for permission to publish this case.

Poona.

\section{LEFT FALLOPIAN TUBE FOUND IN LEFT} FEMORAL HERNIA.

BY E. G. RENNY, M.R.C.S. ENG., L.R.C.P. LoND., ASSISTANT SURGEON ANB ANAESTHETIST ESSEX COUNTY HOSPITAL, GOLCHESTER.

I REPORT the following case as I can find no record of a Fallopian tube presenting in a femoral hernia.

The patient, aged 42, married, mother of three children, had noticed a lump in the left groin for 18 months. During the last five weeks it had become painful, and thinking it was a rupture she bought a truss and wore it. The effect of wearing the truss was to make the lump very painful and inflamed. She then asked me to see her. I found a painful swelling in the groin which, on account of the inflammation present, made the diagnosis uncertain. It was dull to percussion, not reducible, and had no impulse on coughing. No strangulation symptoms were present. The finger could be passed up the inguinal canal for a short distance. Rest was advised, and when the inflammation had subsided (on August 17th) I made an incision over the tumour. It proved to be a femoral hernia with somewhat thickened sac. It contained a considerable quantity of green fluid (under tension). Occupying the crural canal was a red, soft substance, which, when traction was made on it, proved to be the left Fallopian tube with its fimbriated extremity presenting. This was returned to the abdomen without much difficulty, and the sac was ligatured and excised.

Colchester.

Erratum.-In Mr. Irwin Moore's paper on the Operation of Laryngo-fissure Fig. 2 appears upside-down, giving the anæsthetist's and not the surgeon's view of the field. Mr. Moore points out, also, that Dr. Lack's views are incorrectly stated at the end of the article. Dr. Lack does not hold that impairment of voice would follow as described.

\section{attedial Socretirs.}

\section{ROYAL SOCIETY OF MEDICINE.}

SECTION OF OBSTETRICS AND GYN ECOLOGY.

Exhibition of Specimens.-Concealed Accidental Hamorrhage.-Aoute Toxemia of Pregnanoy.-Casarean Seotion and Hysterectomy for Aocidental Hamorrhage.

A MeEting of this section was held on Oct. 5th, Dr. G. F, BLACKER, the President, being in the chair.

Dr. W. S. A. GRIFrith showed a Lipoma of the Broad Ligament, weighing $13 \mathrm{lb}$. At the operation the tumour was found to be retroperitoneal, extending from the right broad ligament to the under surface of the liver. The peritoneal capsule was incised, and the tumour was gradually enucleated from above downwards. The chief vessels were found down in the pelvis, where the tumour had opened up the broad ligament. The cavity thus left was closed by a purse-string suture and the abdomen closed without drainage. The patient made a good recovery. Only two specimens of lipoma of the broad ligament appear to have been hitherto recorded.

Dr. C. HUBERT RoBERTs showed a large Ureteral Calculus, weighing 275 grains. The patient, aged 30, had been in several London hospitals since the age of 17 with symptoms pointing to renal calculus or tuberculosis. The diagnosis of ureteral calculus or calcified gland was made by Dr. Roberts in 1914, when the patient was pregnant. After delivery she was not seen until June 9th, 1916, when she was admitted to the Samaritan Hospital. On laparotomy the right ureter was at once seen, much dilated and thickened, above the stone. The stone was removed, drainage being provided by making an opening in Douglas's pouch through to the vagina. The patient made an uninterrupted recovery.

Dr. Roberts (for Mr. Frank BeLBen) also showed a large Vesical Calculus weighing $3 \frac{1}{2} \mathrm{oz}$., formed around a slate pencil, and removed by suprapubic cystotomy from a girl aged 17. A small stone was also present. Some difficulty was encountered, as the bladder was contracted round the large stone and the pencil had ulcerated into the bladder wall. The patient made a good recovery.

Dr. RoBERTS also showed an instrument invented by the late Dr. Wallace, of Liverpool, for opening Douglas's pouch per vaginam during an abdominal operation.

Dr. CUTHBerT LOCKYER showed a series of Calculi : 1. Small calculus removed from upper part of ureter; good recovery. 2. Two calculi removed from lower end of ureter in patient, aged 63, being operated upon for uterine fibroid and solid ovarian tumour. The entire ureter was removed. Convalescence prolonged by formation of perinephric abscess, which was opened and drained. 3. Calculus from a patient from whom Dr. Lockyer had previously removed uterus, part of rectum, and part of vagina for new growth-an adenomyoma. ${ }^{2}$ The calculus had formed at the recto-vaginal junction in consequence of a ureteric fistula. It was removed per vaginam. 4. Large calculus $5 \frac{1}{2}$ inches in circumference removed from bladder of patient who had a vesico-cervicovaginal fistula, following difficult labour; calculus was removed during operation for closure of fistula.

Remarks were made by Dr. RoberTs, Mr. Douglas Drew, and Dr. GRIFEITH.

Dr. A. J. MCNAIR read a short communication on a case of entirely Concealed Accidental Hæmorrhage, with Intraperitoneal Bleeding.

Mr. Carlton OLdFiel D and Mr. Regrnald Hann related a case of Acute Toxæmia of Pregnancy with Accidental Hæmorrhage, Treated by Cæsarean Hysterectomy; Recovery. It was suggested that accidental hæmorrhage is in some cases, like the one reported, a symptom of pregnancy toxæmia, and the opinion was expressed that in severe cases of accidental hæmorrhage, in which the cervix is elosed, the patient should be delivered by Cæsarean section.

Dr. W. FLETCHER SHAW read a paper on Cæsarean Section and Hysterectomy for Accidental Hæmorrhage. In a very few cases of accidental hæmorrhage no method of treatment has the slightest effect upon the uterine muscle, which

1 Trans. Royal soc. Med., 1915, viii., No. 5, p. 47 